\title{
Isolation and Identification of Pesticides Degrading Bacteria from Farmland Soil
}

\author{
Md. Atikur Rahman ${ }^{1}$, ASM Shamsul Arefin², Otun Saha ${ }^{1}$, Md. Mizanur Rahaman $^{1 *}$ \\ ${ }^{1}$ Department of Microbiology, University of Dhaka, Dhaka-1000, Bangladesh, ${ }^{2}$ Department of Biomedical Physics \& Technology, University of Dhaka, \\ Dhaka-1000, Bangladesh
}

\begin{abstract}
Pesticides are recognized to be the threat to the environment and associated with a wide range of serious diseases including respiratory diseases, cancer and even birth defects. In this study, six-different bacterial strains capable of degrading Carbofuran, Emamectin Benzoate and Thiamethoxam were isolated from eight different soil samples. The isolates were characterized by using different conventional and molecular methods. The strains were identified molecularly into different genotypes using amplified ribosomal DNA restriction analysis (ARDRA) and partial sequencing of 16S rDNA. The ARDRA pattern clustered them into 3 groups. Among the isolates three were identified as Achromobacter spp. and one as Diaphorobacter sp. by biochemical tests. It was further confirmed by the partial 16S rDNA sequencing. The two identified potential bacteria can be used for biodegradation of different pesticides which can have a significant environmental impact in soil farm.
\end{abstract}

Keywords: Pesticides as environmental hazard, pesticide biodegradation, microbial bioremediation, microbial biotransformation, pesticide degrading bacteria.

\section{Introduction}

Agriculture has always been the most important sector of Bangladesh because of its contribution of food, employment and almost $20 \%$ contribution in national GDP ${ }^{1}$. In order to maintain the huge amount of agricultural production, with the application of high-yielding-seeds and proper fertilizers, huge amount of quality pesticides have also been used. The excessive application of pesticides also leads to the accumulation of huge amounts of pesticide in soil and water affecting food chain and drinking water. As a result, pesticides became a substantial health hazard due to the uptake and accumulation of these toxic compounds ${ }^{2}$. Bioremediation using microorganisms, like specific bacterial isolates to transform pollutants to a nontoxic level is getting popular in the research community as it is less expensive and can selectively achieve complete destruction of the organic pollutants ${ }^{3}$. In order to achieve proper bioremediation, specific microbial strains that can effectively degrade the pesticide in situ are required.

Carbofuran with the IUPAC 2, 2-Dimethyl-2, 3-dihydro-1benzofuran-7-yl methylcarbamate is a systemic insecticide and is used mainly to control insects in a wide variety of field crops including, potatoes, corn and soyabeans and it is highly toxic to vertebrates including monkey, tiger, dog and rat and it is particularly toxic to birds. Carbofuran is an endocrine disruptor and a probable reproduction/development intoxicant and it has one of the highest acute toxicities to humans of any insecticide used on field crops ${ }^{4}$.
Emamectin benzoate (4"-deoxy-4"-methylamino derivative of abamectine) is salt with benzoic acid. Emamectin has chloride channel activation properties and is widely used in controlling lepidopterous pests and sea lice. Thiamethoxam with the IUPAC 3-[(2-Chloro-1, 3-thiazol-5-yl) methyl]-5-methyl- $N$-nitro-1, 3, 5oxadiazinan-4-imine is a systemic insecticide Thiamthoxam is also considered as moderately hazardous to human as it is harmful if swallowed. It is non-toxic to fish and algae, mildly toxic to birds and highly toxic to midges and bees 5 .

Various studies suggested that a wide range of microorganisms are capable of degrading pesticides ${ }^{6}$. Most notable among the pesticide degrading bacteria are Pseudomonas, Bacillus, Flavobacterium, Alcaligenes, Arthrobacter, etc ${ }^{7}$. Microorganisms have demonstrated a significant capacity for the metabolism of the pesticides and their metabolism of pesticide is unique than other organisms in that they can completely mineralize many aliphatic, aromatic and heterocyclic compounds ${ }^{8}$. Isolation of indigenous bacteria capable of metabolizing specific pesticides is getting much attention and is considered as an effective tool for bioremediation of pesticides. The present investigation was aimed to identify and isolate pesticides degrading bacteria from soil samples in Bangladesh.

\section{Materials and Methods \\ Collection of sample from soil}

Eight different soil samples were collected from farmlands near to Savar, Gajipur, Keraniganjand Narayanganjin Bangladesh in 
duplicates. In each case, one sample was collected from soil contaminated with pesticides and another from pesticides free soil. Samples were collected in sterile polythene bags and were transferred aseptically to the laboratory.

\section{Enrichment and Isolation of bacteria}

Minimal media containing pesticide as a sole carbon source was used to isolate pesticide degrading bacteria. Carbofuran, Emamectin Benzoate and Thiamethoxam pesticides were used at concentrations of $0.1 \%, 0.5 \%$ and $1 \%$ respectively. Bushnell Haas broth medium containing Cabofuran at different concentration was used for the initial selective enrichment and Bushnell Haas agar medium having different concentration of pesticides was used for the isolation of bacteria ${ }^{9}$. Initially, Carbofuran pesticide was the only carbon source for isolating these isolates in the Bushnell Haas agar. After isolation, these isolates were subcultered in Thiamethoxam and Proclaim (Emamectin Benzoate) containing Bushnell Haas agar.

\section{Morphology and Biochemical Identification}

All the isolates were cultured on nutrient agar medium to observe their colony morphology and microscopic observation was carried out for Gram staining, size and shape. Isolates were characterized by their response to different biochemical tests including Kligler Iron agar (KIA), Motility Indole Urease (MIU), Methyl-Red (MR), Voges-Proskauer (VP), Triple Sugar Iron (TSI), citrate utilization, catalase and oxidase tests ${ }^{10}$ according to the methods described in " Mannual of Methods for General Bacteriology (ASM, 1981)"11.

\section{Molecular characterization of the isolates}

Amplified rDNA restriction analysis (ARDRA) method and partial sequencing of $16 \mathrm{~S}$ rDNA gene of the isolates were performed for molecular characterization of the isolates. Bacterial DNA was prepared by standard boiling method. PCR was performed to generate $16 \mathrm{~s}$ rDNA amplicons using forward primer: 52 -AGAGTTTGATCMATGGCTCAG-32 and reverse primer: 52 -GGTTACCTTGTTACGACTT-32 ${ }^{12}$.Using this universal primer set the product size would be $1466 \mathrm{bp}$. Reaction conditions of thermal cycler were: initial denaturation at $95{ }^{\circ} \mathrm{C}$ for $5 \mathrm{~min}$, followed by 35 cycles of $1 \mathrm{~min}$ at $94{ }^{\circ} \mathrm{C}, 1 \mathrm{~min}$ at $58^{\circ} \mathrm{C}$, and 1 min at $72{ }^{\circ} \mathrm{C}$ with a final extension of $10 \mathrm{~min}$ at $72{ }^{\circ} \mathrm{C}$. For ARDRA, a single restriction enzyme AluI (Thermo Fisher Scientific, USA) was used for the digestion of 16s rDNA amplicons overnight at $37{ }^{\circ} \mathrm{C}^{13}$. After digestion, the products were resolved in $1.5 \%$ agarose gel using $100 \mathrm{bp}$ DNA ladder as size marker. For partial sequencing of 16S rDNA gene, the 16s rDNA amplicons were purified with the Wizard PCR SV Gel and PCR Clean-Up System kit (Promega, USA). The purified PCR products were sequenced by automated cycle sequencing from DNA sequencing lab of First BASE Laboratories, Malaysia.

\section{Bioinformatic analysis}

Sequences were assembled in SeqMan Genome Assembler and the complete sequences were blasted at NCBI to identify individual strains. Phylogenetic and molecular evolutionary analyses were conducted using the MEGA version 7.0 software package. Trees were generated using neighbor-joining algorithm with 1000 bootstrap replication ${ }^{14}$.

\section{Results}

\section{Isolation and Morphological Characterization}

6-Different bacterial isolates that can degrade all 3 pesticides analyzed were screened from the soil samples and named as PDB1, PDB-2, PDB-3, PDB-4, PDB-5 and PDB-6.Initially, 1.0\% carbofuran was the only carbon source for isolating these bacteria in the Bushnell Haas agar media. After isolation, these isolates were grown in Bushnell Haas Media containing 1.0\% Thiamethoxam and 1.0\% Emamectin Benzoate for screening isolated bacterial colony characteristics on Bushnell Haas agar and nutrient agar medium were recorded and microscopic observation was carried out after Gram staining. Among the 6 isolates 4 were Gram negative and 2 were Gram positive (Figure 1).

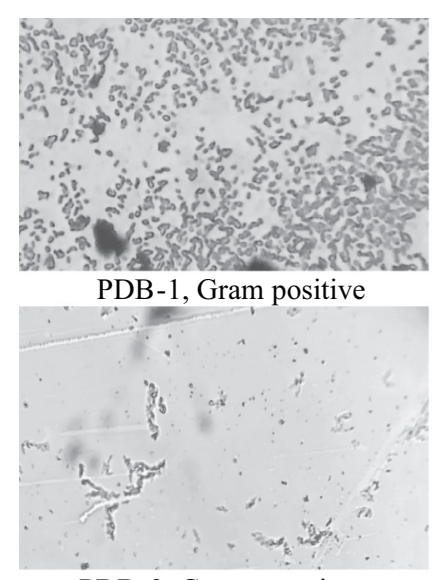

PDB-3, Gram negative

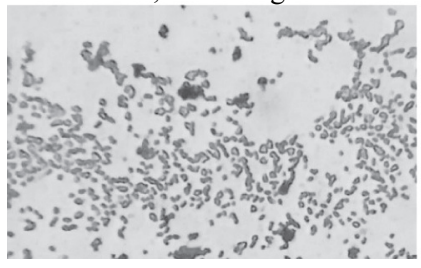

PDB-5, Gram positive

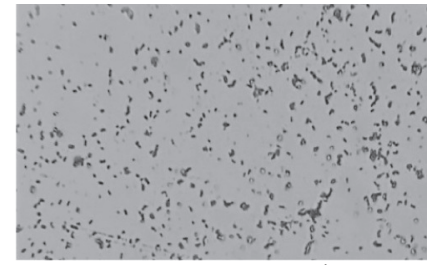

PDB-2, Gram negative

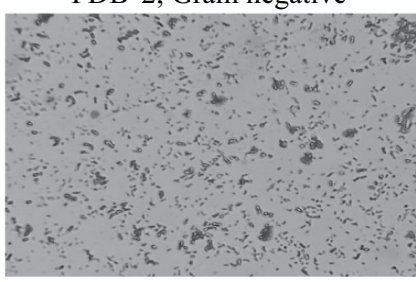

PDB-4, Gram negative

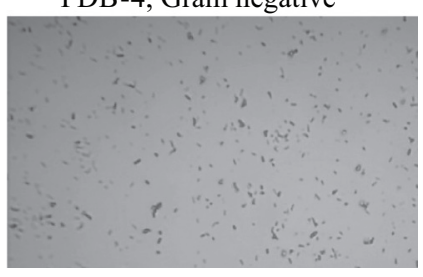

PDB-6, Gram negative
Figure 1. Microscopic observation of the 6 bacterial isolates after Gram reaction

\section{Biochemical Characterization}

The presumptive identification Weser performed using the biochemical tests that are listed in the Table-1. Some of the biochemical properties of the isolates are presented in Table 1

\section{Molecular Identification of the bacterial isolates}

Bacterial 16S rDNA gene was amplified by universal 16S rDNA specific primers. The expected product of around $1.5 \mathrm{~kb}$ (1466 bp exactly) was observed in case of all isolates. The results are 
Table1. Biochemical Characteristics of the isolates

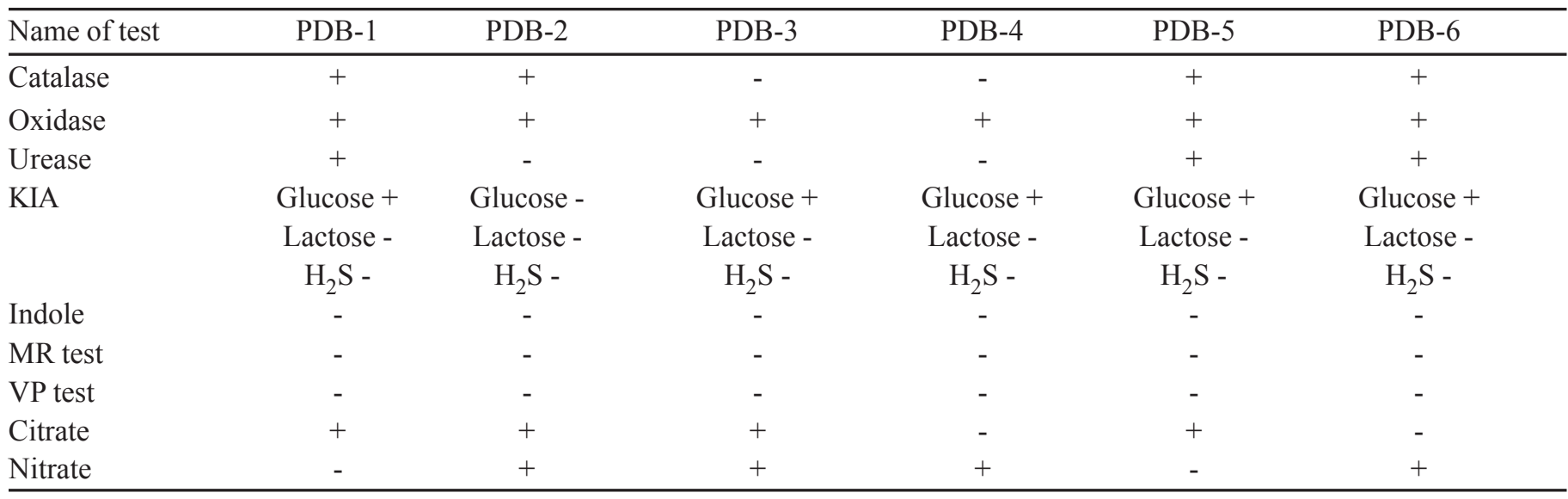

demonstrated in Figure 2 which shows a distinct single band. ARDRA analysis using this amplified 16S rDNA digested with Alu1 restriction enzyme showed 3 ARDRA patterns (Figure-3), pattern 1 includes PDB2, PDB3 and PDB4, pattern 2 includes PDB6, while pattern 3 includes PDB1 and PDB5. This three patterns matches with the biochemical tests. After carrying out ARDRA analysis, 3 strains PDB1, PDB2 and PDB6 were selected from each of the ARDRA patterns for 16SrDNA sequencing. .
The phylogenetic tree was constructed using MEGA software after multiple alignments with 16S rRNA gene sequences of other bacteria with CLUSTALW. The obtained sequence data were compared using 1466 bases. Distances (distance option according to the Kimura two-parameter model) and clustering with the neighbor-joining method were determined by using bootstrap values based on 1000 replications. The result is displayed in Figure 4. It is observed that the isolated strain PDB-2 has

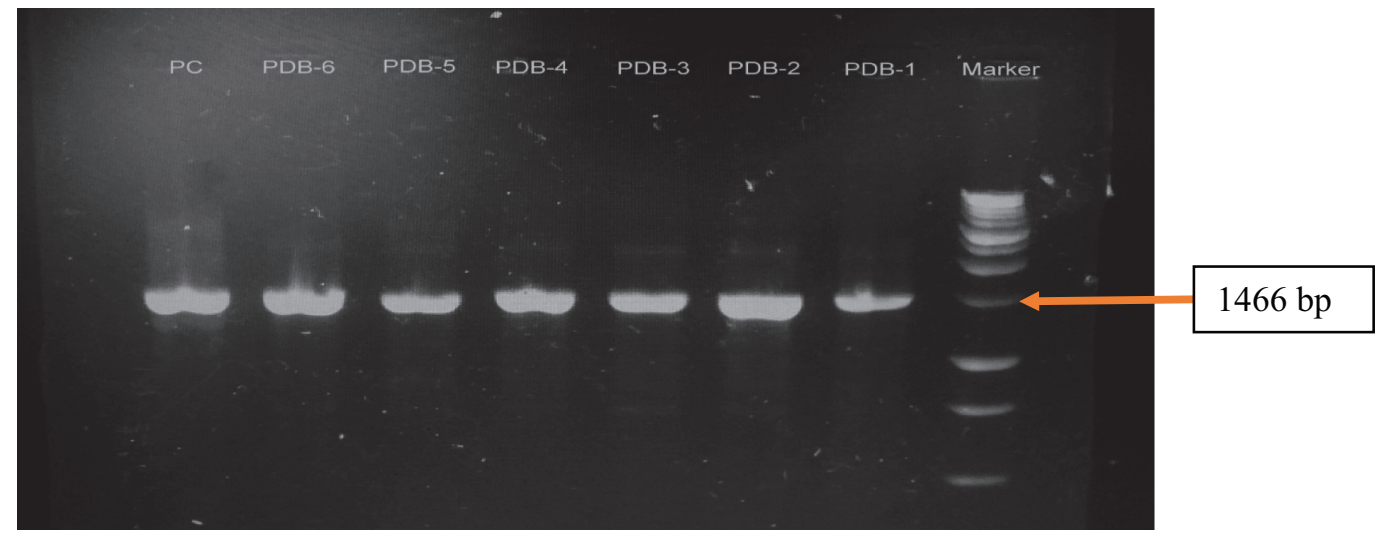

Figure 2. Amplification of $16 \mathrm{~S} \mathrm{rDNA}$ [Here, Marker-1 $\mathrm{kb}$ ladder, PDB 1-6 contain approximately $1.5 \mathrm{~kb}$ band and PC-positive control]

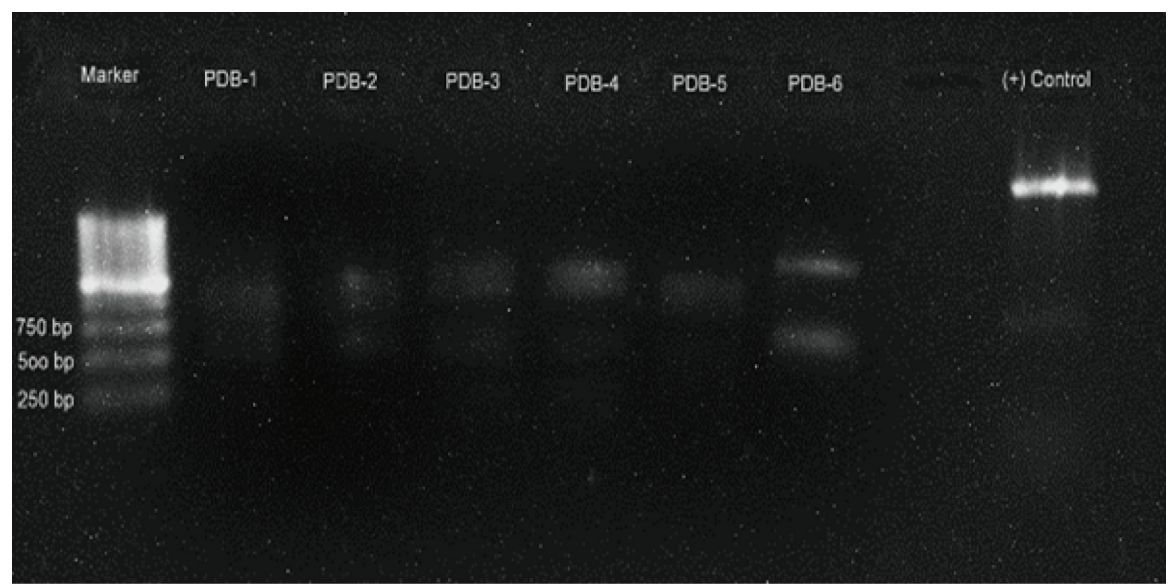

Figure 3. Overview of patterns obtained after Amplified Ribosomal DNA Restriction Analysis. Here, marker- 100 bp ladder and (+) control - uncut 16sr DNA PCR product. Pattern-1 includes PDB2, PDB3, PDB4; Pattern-2 includes PDB6; and pattern-3 includes $P D B 1$ and $P D B 5$ 


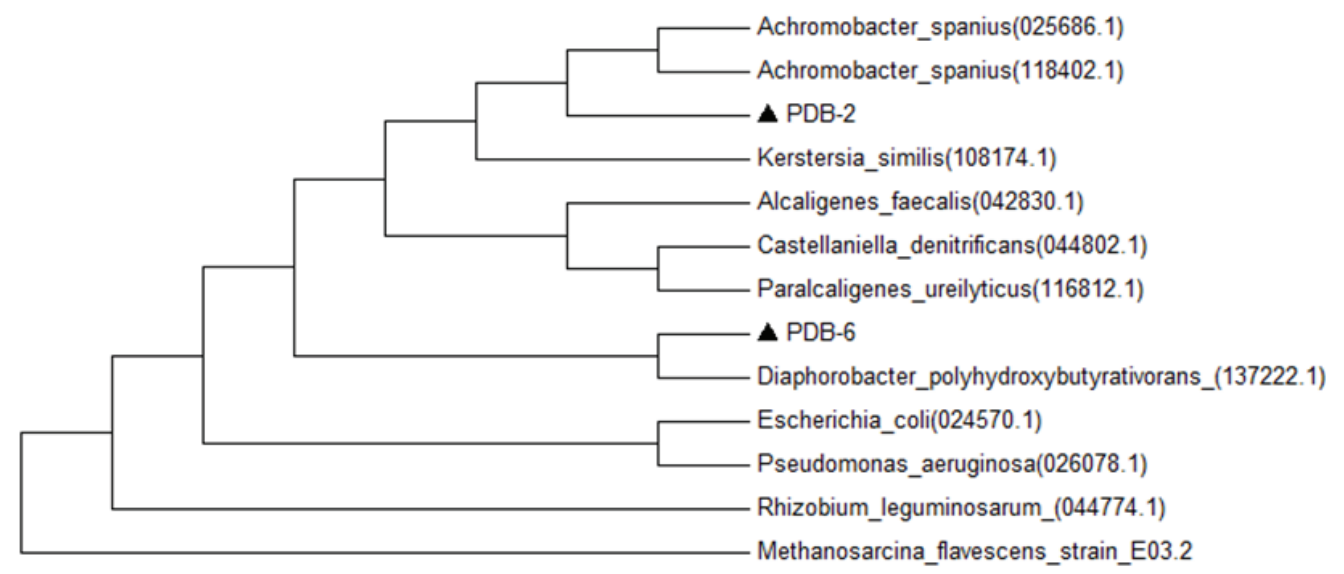

Figure 4. Phylogenetic tree based on $16 S$ rRNA gene sequence comparison showing the position of PDB-2 ,PDB-6 and related species.

similarity with Achromobacter spanius and PDB-6 has similarity with Diaphorobacter polyhydroxybutyrativorans. PDB1 could not be identified due to the poor output of the 16SrDNA sequence data.

\section{Discussion}

All the pesticides have in common that they are applied extensively over large areas in urban and rural areas and these persist in the environment for long time and the residues of many pesticides have been found in drinking water ${ }^{15}$. A quick and robust bioremediation is essential. The present study thus takes the purpose of identifying indigenous bacteria in soil samples in Bangladesh for bioremediation of pesticides from the agriculturebased lands in Bangladesh.

Four different locations of Bangladesh were selected for the collection of soil samples and was performed as previous reports suggested the isolation of some pesticide degrading bacteria from pesticide-applied land only ${ }^{16-17}$. This is because the adaptation of the bacteria with the pesticides and also in many cases, pesticides increased the growth rate of the bacteria that can degrade pesticides ${ }^{18,19}$. Using minimal media like Bushnell Haas allows the sole carbon source as pesticides and hence, it is easy to void the bacteria that are not able to degrade pesticides. Hence, those bacteria that could grow in 3-5 days in this study are those who can actually degrade the pesticides that were applied. Although, metabolite studies are not conducted, it can be assumed that chemical and enzymatic pesticide hydrolysis have been occurred.

Pesticide degrading bacteria that were identified so far includes both Gram positive and Gram-negative bacteria ${ }^{20}$. This study also revealed both Gram-positive and Gram-negative bacteria, although we could not identify properly the Gram-positive bacteria because of the inefficient sequencing data. The sequencing program were run through BLAST program in NCBI and it was found that the query sequence of PDB-2 matched $99 \%$ with the 16S ribosomal RNA sequence (JQ659793.1)
Achromobacter spanius strain R5-793; while the query sequence of PDB-6 matched 98\% with the rRNA sequence of (NR 137222.1) Diaphorobacter Polyhydroxybutyrativorans strain SL205.The phylogenetic tree constructing by neighbor-joining method further revealed that PDB-2 is similar to Achromobacter spanius and PDB-6 is similar to Diaphorobacter polyhydroxybutyrativorans strain. The members of the isolated genera, Achromobacter and Diaphorobacter have the biodegradation capability of other pesticides reported by others researchers $10,21,22$. Thus, this study holds great potential in the bioremediation of pesticides. Very little information is available on pesticides degrading bacterial isolates that can be used practically to treat pesticides contaminated soil. The present study indicates that the bacteriaAchromobacter spanius and Diaphorobacter polyhydroxybutyrativorans were isolated from farmland can degrade pesticides at very low concentration. These strains can be improved through different biotechnological methods to treat contaminated soil.

\section{Conflict of Interest}

The authors declare no conflict of interest.

\section{Acknowledgement}

The financial assistance of the University Grants commission of Bangladesh for funding this research is acknowledged. The authors thank Professor Dr. Anwar Hossain and Mr. Anwar Siddique, Department of Microbiology, University of Dhaka this support during the study.

\section{References}

1. Mohajan, H. 2013. Food, agriculture and economic situation of Bangladesh. Proceedings of 2nd International Conference on Global Sustainable Development (2nd ICGSD-2013), held on 05-06, October, 20131-33

2. Aktar, W., Sengupta, D., \& Chowdhury, A. 2009. Impact of pesticides use in agriculture: their benefits and hazards. Interdisciplinary toxicology., 2(1): 1-12. 
3. R.J. Gilliom et al. 2006. in The Quality of our Nation's Waters, 19922001, U.S. Department of the Interior, U.S. Geological Survey, Eds. (Reston, VA, 2006)

4. Eddleston, M., Buckley, N. A., Eyer, P. \& Dawson, A. H. 2008. Management of acute organophosphorus pesticide poisoning. The Lancet., 371: $597-607$

5. FAO Specifications and Evaluations for Agricultural Pesticides: Thiamethoxam" (PDF). 21 June 2000.

6. Rani, M. S. et al. 2008. Isolation and characterization of a chlorpyrifosdegrading bacterium from agricultural soil and its growth response. African Journal of Microbiology Research., 2: 26-31.

7. Jilani, S. \& Altaf Khan, M. 2004. Isolation, characterization and growth response of pesticides degrading bacteria. J. Biol. Sci., 4: 15-20.

8. Alexander, M. 1969. Microbial degradation and biological effects of pesticides in soil. Soil Biol. Rev. Res. Nat. Resour. Res., (UNESCO) 9:209240 .

9. Looe, IL A. 1975. Indicator media for microorganism degrading chlorinated pesticides. Can. J. Microbiol., 21:104-107.

10. Xia, Z.-Y. et al.2017. Biodegradation of the Herbicide 2, 4Dichlorophenoxyacetic Acid by a New Isolated Strain of Achromobacter sp. LZ35. Current microbiology., 74: 193-202.

11. Buchanan, R. E. and Gibbons, and N. E., eds.1974. Bergey's Manual of Determinative Bacteriology. 8th Ed.

12. Mohanta, M. K., Saha, A. K., Zamman, M. T., Ekram, A. E., Khan, A. S., Mannan, S. B., \& Fakruddin, M.2012. Isolation and characterization of carbofuran degrading bacteria from cultivated soil. Biochem Cell Arch., 12(2): 313-320.

13. Rousseaux, S., Hartmann, A., \& Soulas, G. 2001. Isolation and characterisation of new Gram-negative and Gram-positive atrazine degrading bacteria from different French soils. FEMS Microbiology Ecology., 36(2-3): 211-222.

14. Kumar, S., Stecher, G., and Tamura, K.2016. MEGA7: Molecular Evolutionary Genetics Analysis version 7.0 for bigger datasets. Molecular biology and evolution., 33(7):1870-1874.

15. Michael C.R. Alavanja, Dr. P.H. 2009. Pesticides Use and Exposure Extensive Worldwide Introduction: pesticides use and exposure extensive worldwide. Reviews on environmental health., 24(4): 303-9.

16. Nicolopoulou-Stamati, P., Maipas, S., Kotampasi, C., Stamatis, P., \& Hens, L. 2016. Chemical Pesticides and Human Health: The Urgent Need for a New Concept in Agriculture. Frontiers in public health., 4: 148.

17. Mónica, P., Darwin, R. O., Manjunatha, B., Zúñiga, J. J., Diego, R., Bryan, R. B., ... \& Maddela, N. R. 2016. Evaluation of various pesticidesdegrading pure bacterial cultures isolated from pesticide-contaminated soils in Ecuador. African Journal of Biotechnology., 15(40): 2224-2233.

18. Shalaby Sh. E.M. \& Abdou G. Y. 2010. The influence of soil microorganisms and bio- or - organic fertilizers on dissipation of some pesticides in soil and potato tube. Journal of Plant Protection Research., 50 (1): 86-92.

19. Russell R. J. et al. 2011. The evolution of new enzyme function: lessons from xenobiotic metabolizing bacteria versus insecticide-resistant insects. Evol., 4:225-248.

20. DeLorenzo M. E., Scott G. I. \& Ross P. E. 2001. Toxicity of pesticides to aquatic microorganisms: A review. Environ. Toxicol. Chem., 20: 84-98.

21. Ren, H. F., Li, S. Q., Liu, S. J., \& Liu, Z. P. 2005. Isolation and characterization of a p-chloroaniline-degrading bacterial strain. Huanjing kexue., 26(1): 154-158.

22. Verhagen, P., De Gelder, L., Hoefman, S., De Vos, P. \& Boon, N.2001. Planktonic versus biofilm catabolic communities: importance of the biofilm for species selection and pesticide degradation. Applied and environmental microbiology., 77:4728-4735. 